\title{
Pengembangan Pembelajaran Jarak Jauh Bidang Kimia : Pemanfaatan Teknologi Informasi dalam Pembelajaran Kimia
}

\author{
Yenny Febriani Yun, Sari Purbaya, Abdi Wadud Safe'i, Dewi Meliati Agustini, \\ Rahmaniar Mulyani, Anggi Suprabawati, Hernandi Sujono, Lilis Siti Aisyah, Valentina \\ Adimurti K., Arie Hardian, Jasmansyah, Senadi Budiman, Trisna Yuliana, Sukrido, \\ Anceu Murniati, Muljadji Agma
}

Jurusan Kimia, Fakultas Sains dan Informatika

Universitas Jenderal Achmad Yani

Penulis korespondensi : yenny.febriani@lecture.unjani.ac.id

\begin{abstract}
Abstrak: Perkembangan metode pembelajaran saat ini terus berkembang seiring berkembangnya ilmu pengetahuan dan teknologi. Termasuk dalam situasi pandemi seperti ini, diperlukan media pembelajaran yang memadai agar tujuan belajar mengajar tercapai. Namun sampai saat ini media pembelajaran interaktif belum berkembang dengan optimal di Indonesia, meliputi tingkat pemahaman dan tingkat keterampilan guru dan dosen yang masih rendah. Maka upaya yang dilakukan untuk mengatasi situasi permasalahan tersebut di atas yaitu dengan memberikan beberapa materi yang terkait dengan upaya mengembangkan media pembelajaran interaktif agar pembelajaran yang diberikan meningkatkan minat dan kualitas belajar siswa. Bentuk kegiatan yang cocok yaitu webinar series dan workshop pelatihan pembuatan media pembelajaran secara interaktif. Pendekatan yang dilakukan melalui kegiatan webinar tentang literasi sains kimia dan workshop on line tentang kimia komputasi. Hasil kegiatannya yaitu untuk meningkatkan pemahaman masyarakat tentang pemanfaatan teknologi dan pengembangan media pembelajaran interaktif maka diperlukan suatu kegiatan berbentuk webinar yang bermanfaat bagi mereka dan menjelaskan bagaimana mengembangkan dan membuat media pembelajaran yang mudah dan dapat diterima oleh siswa dan mahasiswa, sedangkan untuk meningkatkan keterampilan diperlukan kegiatan workshop/pelatihan dalam rangka meningkatkan pembuatan media belajar yang atraktif.
\end{abstract}

Kata kunci: metode pembelajaran, situasi pandemi, webinar series, workshop pelatihan, dosen, guru

Abstract: The development of learning methods is currently developing along with the development of science and technology. Included in a pandemic situation like this, adequate learning media is needed so that teaching and learning objectives are achieved. However, until now interactive learning media has not developed optimally in Indonesia, including the level of understanding and skill levels of teachers and lecturers which are still low. Then efforts to resolve the situation mentioned above is by providing some material related to develop interactive learning media so that the learning provided increases student interest and learning quality. Suitable activities are webinar series and training workshops for making interactive

Volume 2, Nomor 1, Maret 2021|50

Pengembangan Pembelajaran Jarak Jauh Bidang Kimia : Pemanfaatan Teknologi Informasi dalam Pembelajaran Kimia

Yenny Febriani Yun, Sari Purbaya, Abdi Wadud Safe'i, Dewi Meliati Agustini, Rahmaniar Mulyani, Anggi Suprabawati, Hernandi Sujono, Lilis Siti Aisyah, Valentina Adimurti K., Arie Hardian, Jasmansyah, Senadi Budiman, Trisna Yuliana, Sukrido, Anceu Murniati, Muljadji Agma https://doi.org/10.26874/jakw.v2i1.97 
learning media. The approach is carried out through webinars on chemical science literacy and online workshops on computational chemistry. The results of the activity, to increase people's understanding of the using of technology and the development of interactive learning media, an activity like webinar is needed that is useful for them and explains how to develop and make learning media that are easy and acceptable to students, whereas to improve skills workshop/training are needed in order to improve the making of attractive learning media.

Keywords: learning methods, pandemic situations, webinar series, training workshops, lecturers, teachers

\section{Pendahuluan}

Perkembangan metode pembelajaran saat ini terus berkembang seiring berkembangnya ilmu pengetahuan dan teknologi. Kemajuan teknologi harus masuk ke dalam kurikulum agar siswa dapat memanfaatkan teori yang di dapat yang kemudian dikaitkannya dengan teknologi saat ini. Sebagai contoh, Blonder dan Sakhnini telah menemukan koneksi antara kurikulum SMA dengan sains dan teknologi skala nano (Blonder \& Sakhnini, 2017), Boddey dan Berg, telah melaporkan dampak pengalaman kimia sebelumnya mahasiswa keperawatan pada kinerja akademik dan persepsi relevansi dalam kursus ilmu kesehatan (Boddey \& Berg, 2014), Marks dan Eilks melakukan pengembangan rencana pembelajaran berbasis penelitian tentang gel mandi dan wewangian dengan mengikuti social kritis dan berorientasi pada pengajaran kimia (Marks \& Eilks, 2010), dan Burmeister dan Eilks membuat percontohan pembelajaran tentang plastik dan evaluasinya sebagai kontribusi untuk pendidikan dan pembangunan berkelanjutan dalam pengajaran kimia sekolah menengah atas (Burmeister \& Eilks, 2012). Pembuatan rencana pembelajaran berbasis penelitian memang sudah seharusnya dilakukan untuk membawa siswa lebih memahami kondisi yang ada di sekitar mereka.

Komunikasi tidak akan berjalan tanpa bantuan sarana penyampai pesan atau media, demikian pula komunikasi dalam pembelajaran pada situasi pandemi yang memerlukan media pembelajaran yang memadai agar tujuan belajar mengajar tercapai. Sampai saat ini media pembelajaran interaktif belum berkembang dengan optimal di Indonesia. Salah satu kendala pengembangan media pembelajaran interaktif adalah kurang dikuasainya teknologi pengembangan media interaktif oleh para pengajar, sehingga pengembangan materi pembelajaran interaktif dengan komputer kurang optimal (Ronald, 1994).

Berdasarkan analisis situasi di atas, maka yang perlu dilakukan untuk mengatasi situasi

Volume 2, Nomor 1, Maret 2021|51

Pengembangan Pembelajaran Jarak Jauh Bidang Kimia : Pemanfaatan Teknologi Informasi dalam Pembelajaran Kimia

Yenny Febriani Yun, Sari Purbaya, Abdi Wadud Safe'i, Dewi Meliati Agustini, Rahmaniar Mulyani, Anggi Suprabawati, Hernandi Sujono, Lilis Siti Aisyah, Valentina Adimurti K., Arie Hardian, Jasmansyah, Senadi Budiman, Trisna Yuliana, Sukrido, Anceu Murniati, Muljadji Agma https://doi.org/10.26874/jakw.v2i1.97 
permasalahan tersebut di atas yaitu dengan memberikan beberapa materi yang terkait dengan upaya mengembangkan media pembelajaran interaktif agar pembelajaran yang diberikan oleh guru dan dosen menjadi lebih atraktif sehingga meningkatkan minat dan kualitas belajar siswa. Bentuk kegiatan yang cocok yaitu webinar series 2 dan workshop pelatihan pembuatan media pembelajaran secara interaktif. Dengan kegiatan yang telah dilakukan oleh Jurusan Kimia FSI Unjani, diharapkan masyarakat akan lebih memahami bagaimana membuat media pembelajaran yang mudah, dapat diterima, dicerna serta dipahami oleh para guru dan dosen, sedangkan workshop ini dikhususkan untuk guru-guru kimia SMA dan dosen untuk memberikan tambahan pengetahuan dan keterampilan bagi mereka dalam hal metode pembelajaran interaktif di kelas.

Ilmu Kimia merupakan cabang ilmu pengetahuan alam atau sains yang berhubungan dengan identifikasi materi seperti komposisinya, sifatnya, dan cara materi berinteraksi, bergabung dan berubah, serta kegunaan proses tersebut untuk membentuk materi baru.

Jurusan Kimia FSI-Unjani adalah salah satu Jurusan di Lingkungan Fakultas Sains dan Informatika (FSI), Universitas Jenderal Achmad Yani (UNJANI), Cimahi yang sedang dan terus mengembangkan diri untuk dapat mengikuti kemajuan ilmu pengetahuan dan teknologi dewasa ini. Jurusan Kimia FSI Unjani berkomitmen menghasilkan lulusan yang berkualitas serta unggul dalam keilmuan maupun disiplin keprofesian sehingga dapat berkompetisi di masyarakat dan bermanfaat bagi kehidupan seluruh umat manusia.Untuk mencapai sasaran di atas, Jurusan Kimia FSI UNJANI selalu berupaya menciptakan suasana akademik yang nyaman, disiplin, dan inovatif sesuai dengan nilai-nilai keluhuran Jenderal Achmad Yani. Jurusan Kimia FSI UNJANI, pendiriannya dirintis sejak tahun 1986 dan sampai saat ini Jurusan Kimia telah mendapatkan status Terakreditasi dengan nilai “B” untuk yang keempat kalinya berdasarkan Keputusan BAN - PT Nomor: 506/SK/BAN-PT/Akred/S/VI/2015 [8].

Dalam menghasilkan lulusan terbaik, Jurusan Kimia FSI Unjani selalu melakukan risetriset terkait tri dharma perguruan tinggi. Hasil riset ini selanjutnya diterapkan dalam pembuatan materi ajar yang selanjutnya dikembangkan dalam pengabdian masyarakat dalam bentuk webinar workshop. Workshop merupakan sebuah kegiatan atau acara yang dilakukan, dimana beberapa orang yang memiliki keahlian di bidang tertentu berkumpul untuk membahas masalah tertentu dan mengajari para peserta workshop.

Volume 2, Nomor 1, Maret 2021|52

Pengembangan Pembelajaran Jarak Jauh Bidang Kimia : Pemanfaatan Teknologi Informasi dalam Pembelajaran Kimia

Yenny Febriani Yun, Sari Purbaya, Abdi Wadud Safe'i, Dewi Meliati Agustini, Rahmaniar Mulyani, Anggi Suprabawati, Hernandi Sujono, Lilis Siti Aisyah, Valentina Adimurti K., Arie Hardian, Jasmansyah, Senadi Budiman, Trisna Yuliana, Sukrido, Anceu Murniati, Muljadji Agma https://doi.org/10.26874/jakw.v2i1.97 
Berdasarkan latar belakang, analisa situasi, dan tinjauan pustaka, maka dapat diidentifikasi permasalahan yaitu kurangnya pemahaman masyarakat awam dalam hal memaknai peran kimia di kehidupan sehari-hari dan akademisi dalam mengatasi kesulitan perihal pembelajaran mengingat kurangnya pemahaman kimia terapan. Dengan demikian, dapat dibuat beberapa rumusan masalahnya yaitu:

1. Bagaimana meningkatkan pemahaman masyarakat umum dalam hal memaknai peran kimia di kehidupannya sehari-hari?

2. Bagaimana cara membantu akademisi dalam mengatasi kesulitannya mereka dalam mentransfer ilmu kimianya?

Maksud dari kegiatan Pengabdian kepada Masyarakat Jurusan Kimia FSI Unjani yaitu meningkatkan pemanfaatan teknologi dalam mengembangkan media pembelajaran interaktif, serta mengembangkan media pembelajaran interaktif agar pembelajaran yang diberikan oleh guru menjadi lebih atraktif sehingga meningkatkan minat dan kualitas belajar siswa. Tujuan dari kegiatan ini yaitu:

1. Meningkatkan pemahaman pemanfaatan teknologi dalam mengembangkan media pembelajaran interaktif

2. Meningkatkan keterampilan guru dan dosen kimia dalam mengembangkan media pembelajaran interaktif agar pembelajaran yang diberikan oleh guru menjadi lebih atraktif sehingga meningkatkan minat dan kualitas belajar siswa

Kegiatan ini juga diharapkan dapat meluruskan sudut pandang masyarakat awam terhadap kimia itu sendiri dan menambah wawasan guru sekolah akan lebih memahami bagaimana membuat media pembelajaran yang mudah, dapat diterima, dicerna serta dipahami oleh para guru dan dosen, sedangkan workshop ini dikhususkan untuk guru-guru kimia SMA dan dosen untuk memberikan tambahan pengetahuan dan keterampilan bagi mereka dalam hal metode pembelajaran interaktif di kelas.

\section{Metode}

Pendekatan yang dilakukan melalui kegiatan webinar tentang literasi sains kimia dan workshop on line tentang kimia komputasi berikut cara menggunakan program-program di dalamnya.

Volume 2, Nomor 1, Maret 2021| 53

Pengembangan Pembelajaran Jarak Jauh Bidang Kimia : Pemanfaatan Teknologi Informasi dalam Pembelajaran Kimia

Yenny Febriani Yun, Sari Purbaya, Abdi Wadud Safe'i, Dewi Meliati Agustini, Rahmaniar Mulyani, Anggi Suprabawati, Hernandi Sujono, Lilis Siti Aisyah, Valentina Adimurti K., Arie Hardian, Jasmansyah, Senadi Budiman, Trisna Yuliana, Sukrido, Anceu Murniati, Muljadji Agma https://doi.org/10.26874/jakw.v2i1.97 
Adapun prosedur kerja dalam mendukung realisasi metode yang ditawarkan dapat dilihat pada Gambar 1.

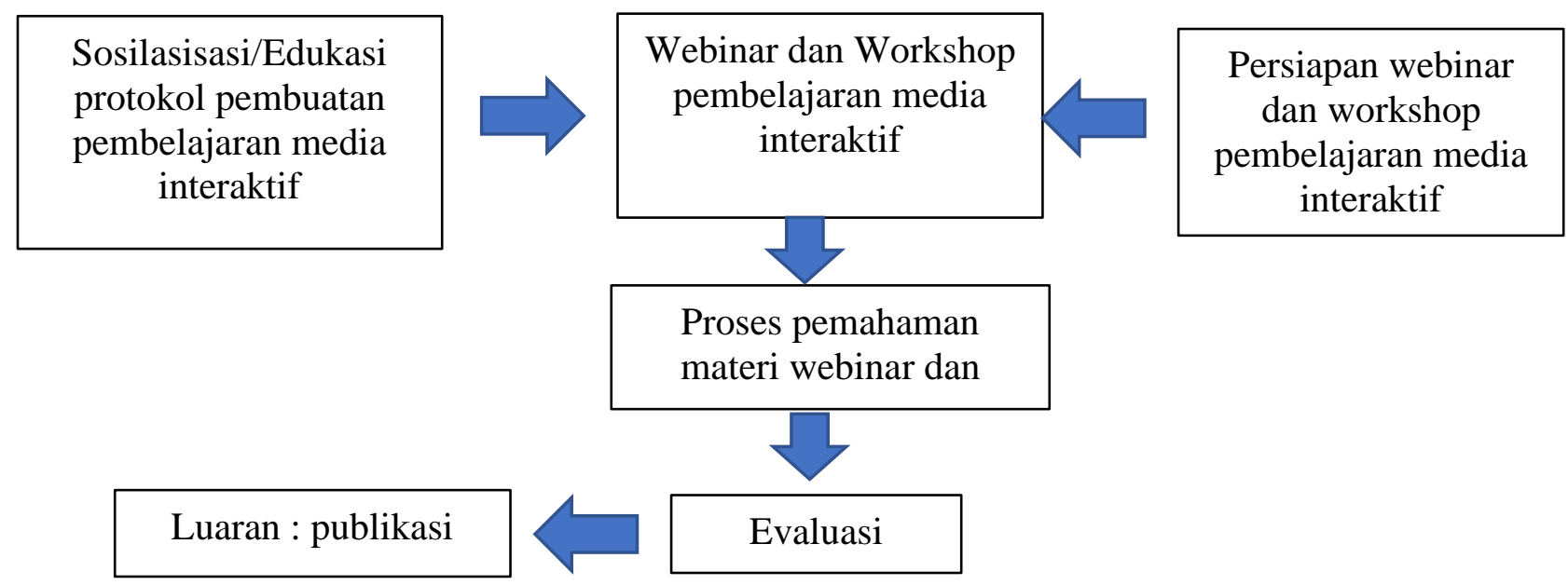

Gambar 1. Prosedur kerja/ Diagram alir Kegiatan Abdimas

Bentuk kegiatan disesuaikan dengan khalayak sasaran, yaitu webinar ditujukan untuk masyarakat umum mengingat penyampaiannya lebih menarik dan mudah dipahami juga memerlukan waktu singkat. Sedangkan workshop ditujukan untuk akademisi karena memerlukan dasar teori yang dimiliki oleh peserta.

Kegiatan dilaksanakan bersamaan dengan kegiatan SNIKA 2020 yaitu 15 Desember 2020. Tempat kegiatan di Jurusan Kimia Fakultas Sains dan Informatika Universitas Jenderal Achmad Yani.

\section{Hasil dan Diskusi}

Terdapat dua pendekatan yang berbeda untuk masing-masing persoalan di atas. Terkait persoalan pertama yakni meningkatkan pemahaman masyarakat tentang pemanfaatan teknologi dan pengembangan media pembelajaran interaktif maka diperlukan suatu kegiatan berbentuk webinar yang bermanfaat bagi mereka dan menjelaskan bagaimana mengembangkan dan membuat media pembelajaran yang mudah dan dapat diterima oleh siswa dan mahasiswa, sedangkan untuk persoalan kedua diperlukan suatu kegiatan berjenis workshop/pelatihan dalam rangka meningkatkan pembuatan media belajar yang atraktif.

Volume 2, Nomor 1, Maret 2021|54

Pengembangan Pembelajaran Jarak Jauh Bidang Kimia : Pemanfaatan Teknologi Informasi dalam Pembelajaran Kimia

Yenny Febriani Yun, Sari Purbaya, Abdi Wadud Safe'i, Dewi Meliati Agustini, Rahmaniar Mulyani, Anggi Suprabawati, Hernandi Sujono, Lilis Siti Aisyah, Valentina Adimurti K., Arie Hardian, Jasmansyah, Senadi Budiman, Trisna Yuliana, Sukrido, Anceu Murniati, Muljadji Agma https://doi.org/10.26874/jakw.v2i1.97 
Kegiatan ini diharapkan akan memberikan wawasan baru dalam pembuatan media pembelajaran, mengingat kemampuan program ini dalam hal pembuatan animasi untuk media pembelajaran multimedia yang menarik dengan caranya relatif mudah. Dengan dikuasainya media pembelajaran multimedia ini diharapkan akan pemicu minat siswa untuk lebih bersemangat dalam mengikuti pelajaran, dan pada akhirnya akan meningkatkan kualitas pembelajaran secara keseluruhan.

Bentuk kegiatan disesuaikan dengan khalayak sasaran mengingat penyampaiannya lebih menarik dan mudah dipahami juga memerlukan waktu singkat dan memerlukan dasar teori yang dimiliki oleh peserta. Mitra berpartisipasi dalam mempersiapkan dan memberikan materi yang menarik dan mudah dipahami, serta melakukan sosialisasi kegiatan.

Khalayak sasaran yaitu masyarakat umum dan akademisi yaitu guru dan mahasiswa. Dalam mengundang khalayak atau sasaran dari kegiatan ini maka telah dibuat dan disebarkan melalui sosial media brosur kegiatan abdimas ini.

a. Workshop Kimia Komputasi

Workshop kimia komputasi bertujuan untuk meningkatkan kemampuan guru kimia dan masyarakat pada umumnya dalam meningkatkan penggunaan software komputasi di bidang kimia dan pembuatan media pembelajaran yang menarik melalui animasi-animasi kimia terutama pembuatan struktur kimia.

b. Webinar Literasi Sains - Kimia

Webinar Literasi Sains - Kimia bertujuan untuk meningkatkan kemampuan guru kimia, siswa, dan masyarakat pada umumnya dalam meningkatkan keterampilan dan kemampuan literasi sains bidang kimia.



Gambar 2. Kegiatan workshop Kimia Komputasi untuk Guru SLTA

Volume 2, Nomor 1, Maret 2021|55

Pengembangan Pembelajaran Jarak Jauh Bidang Kimia : Pemanfaatan Teknologi Informasi dalam Pembelajaran Kimia

Yenny Febriani Yun, Sari Purbaya, Abdi Wadud Safe'i, Dewi Meliati Agustini, Rahmaniar Mulyani, Anggi Suprabawati, Hernandi Sujono, Lilis Siti Aisyah, Valentina Adimurti K., Arie Hardian, Jasmansyah, Senadi Budiman, Trisna Yuliana, Sukrido, Anceu Murniati, Muljadji Agma https://doi.org/10.26874/jakw.v2i1.97 


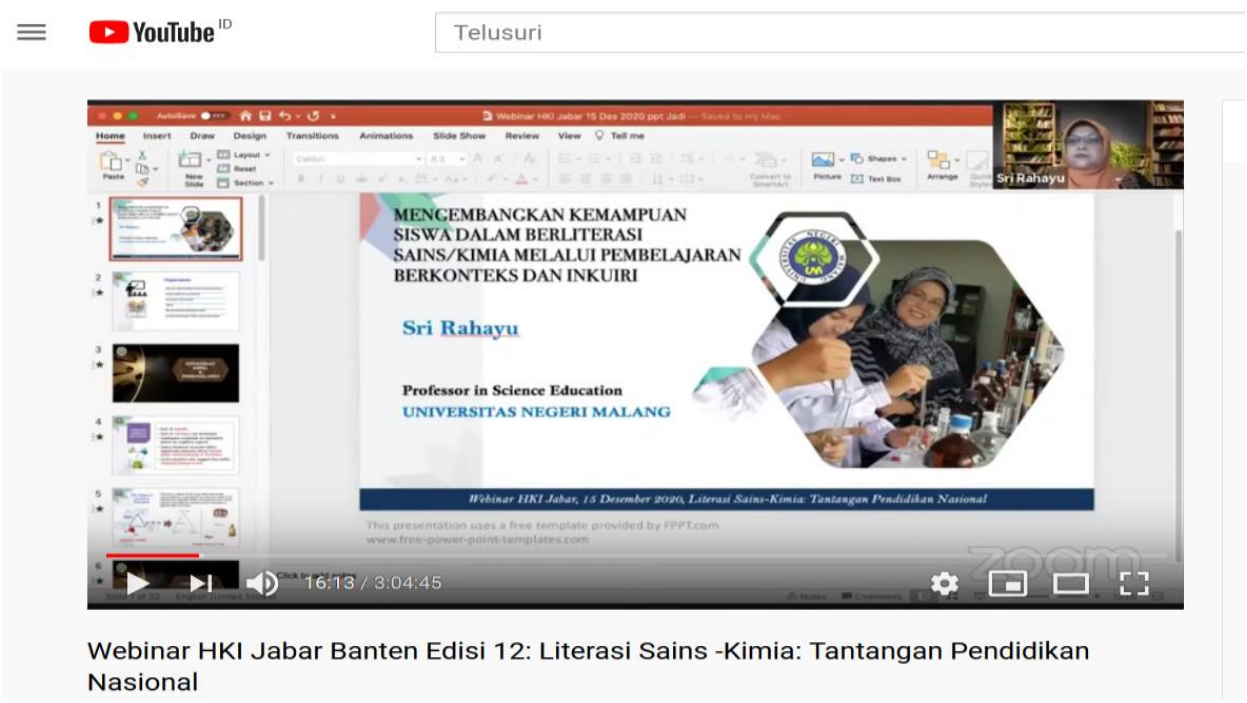

Gambar 3. Kegiatan webinar Literasi Sains - Kimia

Produk teknologi dalam webinar ini sesuai dengan uraian pada Tabel 1.

Tabel 1. Produk teknologi pada kegiatan webinar

\begin{tabular}{|c|l|l|}
\hline No. & Jenis luaran & Produk Teknologi \\
\hline 1 & $\begin{array}{l}\text { Materi Webinar pembelajaran } \\
\text { media atraktif }\end{array}$ & e-materi \\
\hline 2 & Sertifikat & E-sertifikat \\
\hline 3 & Webinar Media pembelajaran & $\begin{array}{l}\text { Wawasan guru bidang kimia bertambah terkait } \\
\text { pengembangan media pembelajaran yang menarik dengan } \\
\text { cara yang relatif mudah }\end{array}$ \\
\hline
\end{tabular}

\section{Kesimpulan}

Berdasarkan kegiatan serta saran dan tanggapan yang diberikan oleh peserta dapat disimpulkan bahwa kegiatan Webinar Media Pembelajaran Jurusan Kimia FSI Unjani ini sangat bermanfaat bagi masyarakat khususnya guru-guru kimia, dalam mempersiapkan media pembelajaran sehingga dapat lebih memahami peran ilmu kimia.

Agar kegiatan lebih meriah dengan peserta yang lebih banyak maka sosialisasi harus lebih ditingkatkan. Diharapkan kegiatan seperti ini dapat berlangsung rutin setiap tahun pada waktuwaktu tertentu.

Volume 2, Nomor 1, Maret 2021| 56

Pengembangan Pembelajaran Jarak Jauh Bidang Kimia : Pemanfaatan Teknologi Informasi dalam Pembelajaran Kimia

Yenny Febriani Yun, Sari Purbaya, Abdi Wadud Safe'i, Dewi Meliati Agustini, Rahmaniar Mulyani, Anggi Suprabawati, Hernandi Sujono, Lilis Siti Aisyah, Valentina Adimurti K., Arie Hardian, Jasmansyah, Senadi Budiman, Trisna Yuliana, Sukrido, Anceu Murniati, Muljadji Agma https://doi.org/10.26874/jakw.v2i1.97 


\section{Ucapan Terima Kasih}

Terima kasih kepada LPPM Unjani dan panitia SNIKA yang telah mendanai kegiatan pengabdian masyarakat ini, serta tak lupa terima kasih atas kerjasamanya kepada HKI Jabar Banten, sehingga kegiatan dapat berlangsung dengan baik.

\section{Daftar Referensi}

Blonder, R. \& Sakhnini, S. 2017. Finding The Connections Between a High-School Chemistry Curriculum and Nano-Scale Science and Technology, Chem. Educ. Res. Pract., 18, $903-$ 922.

Boddey, K. \& Berg, K. 2014. The Impact of Nursing Students' Prior Chemistry Experience on Academic Performance and Perception of Relevance in a Health Science Course, Chem. Educ. Res. Pract., 16, 212-227.

Burmeister, M. \& Eilks, I. 2012. An Example of Learning About Plastics and Their Evaluation as a Contribution to Education for Sustainable Development in Secondary School Chemistry Teaching, Chem. Educ. Res. Pract., 13, 93-102.

Marks, R. \& Eilks, I. 2010. Research-Based Development of a Lesson Plan on Shower Gels and Musk Fragrances Following a Socio-Critical and Problem-Oriented Approach to Chemistry Teaching, Chem. Educ. Res. Pract., 11, 129-141.

Ronald A. 1994. Pemilihan dan Pengembangan Media untuk Pembelajaran, terjemahan oleh Yusufhadi Miarso dkk, PT. Raja Grafindo Persada, Jakarta. 